\title{
LATEST ADVANCEMENTS IN CARBON BASED FIBER, A REVIEW
}

\author{
MANPREET SINGH ${ }^{1} \&$ VINOD KUMAR ${ }^{2}$ \\ ${ }^{1} P G$ Student Department of Mechanical Engineering, Chandigarh University $(C U)$, \\ Gharuan-Mohali Punjab, India \\ ${ }^{2}$ Professor Mechanical Engineering Department, Chandigarh University (CU), \\ Gharuan-Mohali Punjab, India
}

\begin{abstract}
Universal interest in Carbon fiber composites are reflected in manufacturing capability that is increasing day by day. Carbon fiber reinforced polymers (CFRPs) are one the stiffest and lightest composite materials. They are much persuading than other traditional materials. Carbon fibers are from the family of advanced composites materials. This paper is mainly related to the research and development stages of carbon fiber of last few years. Two most predominant precursors are e.g. (Polyacrylonitrile (PAN), Mesophase Pitch (MP)) are in carbon-fiber industry. The structure of Carbon fiber and composition of utilized precursors is directly related with properties of resultant carbon fiber. The production processes of carbon fibers are same and according to requirement, different precursors are used for different processing conditions. This paper represents the review related with various process optimizations, and also tries to cover the study on some other precursor materials development, mostly for the cost reduction. Moreover, carbon fiber composites fabrication techniques, applications and properties are also discussed herewith.

KEYWORDS: Carbon fiber (CF), Polyacrylonitrile, Mesophase Pitch, Fabrication, Applications \& Properties and Structure
\end{abstract}

Received: Jun 23, 2017; Accepted: Jul 14, 2017; Published: Aug 01, 2017; Paper Id: IJMPERDAUG201733

\section{INTRODUCTION}

Carbon-fiber is a well-known material, which contains mostly carbon atoms with 5-10 micrometer in diameter. Carbon fibers are utilized to combine one material with other materials to fabricate a composite. These atoms are attached with each other in microscopic crystals. Carbon fiber has excellent mechanical properties (like ductile properties, low density, and high thermal and chemical resistance). It has also good thermal and electrical conductivity. These are broadly used in composites known as woven materials, reliable strands/roving's, prepregs, and slashed filaments. The carbon fiber industry has become with well usable materials in various fields like aerospace (flying machines and spaceships), military equipment's in turbines (edges) in non-auxiliary and basic frameworks, in light weight drums, automobile, medical area, sports products, and etc. [1].

Now a day, in automobile industry, these polymeric composites are widely used due to its properties of light weight and popular styling. Carbon fiber also used in automobile body parts (doors, interior designing, front and rear bumpers etc.) chassis and shock absorber, drive shaft, and many others. Carbon fiber is characterized as a fiber, which have no less than ninety two \% carbon content, if the fiber has $99 \%$ carbon is generally called a graphite fiber [2]. CF has magnificent ductile properties, high temp, low densities and good sound qualities. For the car business, fiber fortified polymeric composite compromise decreased weight of content and predominant styling. Moreover, Carbon strands can discover the uses in body parts (entryways, hooks, deck covers, guards, and so 
on.), skeleton and shock absorber frameworks (like leaf spring), drive shaft et cetera. The global carbon fiber consumption is given in figure $1.1[2-3]$.

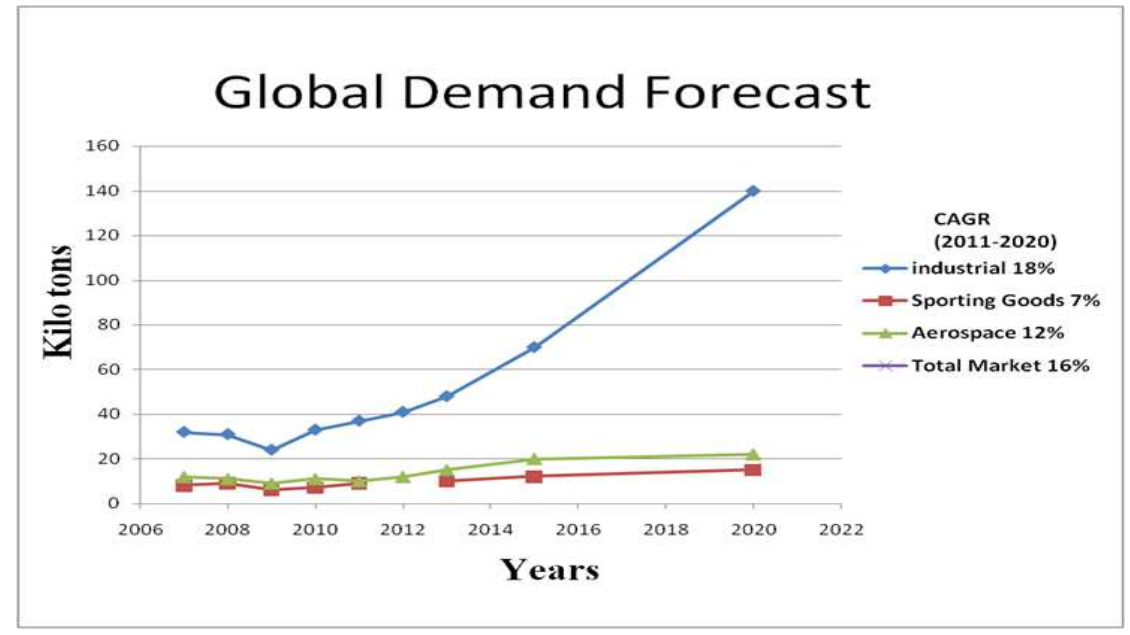

Figure 1: The Worldwide Demand of Carbon Fiber [4]

\section{STRUCTURES, PRECURSOR AND PROPERTIES OF CARBON FIBER}

The carbon fiber atomic structure is same as graphite, which consists of carbon layer; these layers are settled on a continuous hexagonal pattern given below in figure -1.2. On the basis of precursor and production process, the layer plane in carbon fiber (CF) may be graphitic, hybrid, and turbo static structure. The Graphitic structure has crystalline locals; the layer is fitted parallel planes to each other in a customary manner. Molecules in a plane are prepared by sp2 holding, though the communication among sheets is moderately powerless Vander Waals powers. The solitary graphitic gem, dseparating among 2 graphene layers are around to 0.335 NM [2]. C33 has a 36.5 GPA and C11 has a 1,060 GPA individually, however C44 has a low shearing 4.5 GPA. Even though, the fundamental auxiliary unit of numerous carbon filaments comprises of a mass of turbo stratus layer. The parallel graphene sheets stacked unpredictably (randomly) in a turbostratic structure may be collapsed. It results in the nearness of sp3 holding that could be expanded to d-separating at $0.344 \mathrm{~nm}$ [56]. Watt and Johnson [7] treated the Polyacrylonitrile carbon-fiber crystalline structure with a temperature of around $\left(2,500^{\circ} \mathrm{C}\right)$, Results showed, the turbo-stratic crystal has LC (crystalline structure) with no less than twelve layer planes and on another the side (LC), crystallite had a width of 6-12 $\mu \mathrm{m}$. These two (LC and LA) be inclined with increment by high temperature.

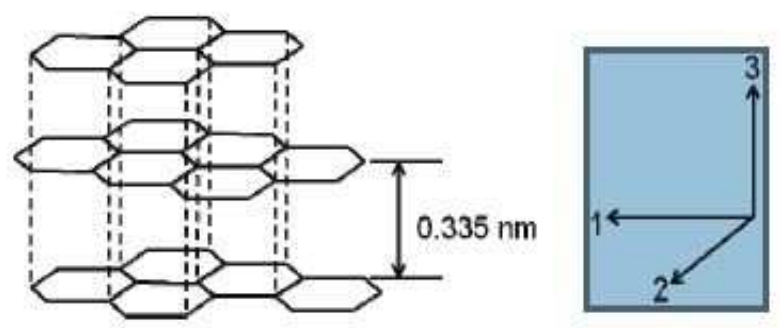

Figure 2: Hexagonal Pattern of Carbon Fiber [8]

Another thing to be kept in mind is, the CF microstructure relies upon the precursor and preparing conditions. 


\section{Polyacrylonitrile (PAN) Carbon Fiber}

Polyacrylonitrile (PAN) carbon fiber contains $68 \%$ carbon content. Today, this is the most famous precursor used for the manufacturing of carbon fiber. In present time, PAN is used as a basis precursor in carbon fiber manufacturing. There are different types of precursor available in the market. Every precursor has different properties and this also changes the properties of carbon fiber. Although every precursor has different production conditions of carbon fiber, but the basic features are same. Fig-1.3 shows the microstructure of PAN carbon fiber.

Watt and Johnson [9] studied that if we cured the structure of PAN carbon fiber at $2500^{\circ} \mathrm{C}$, then we find that less (crystallite structure) and La (crystallite width) having 12 and 612nmlayer planes. These two La and LC incline to grow with heat treatment temperature, as the LC (crystallite structure) and La (crystallite width) incline by growing the heat treatment. Usually, Mesophase Pitch and vapour grown carbon fiber are utilized for a good arranged graphitic crystal structure. However, another precursor like PAN can be used to manufacture in turbo static structure. By rotating and shifting methods, the layer planes can be rearranged, though the ratio of these established methods is small.

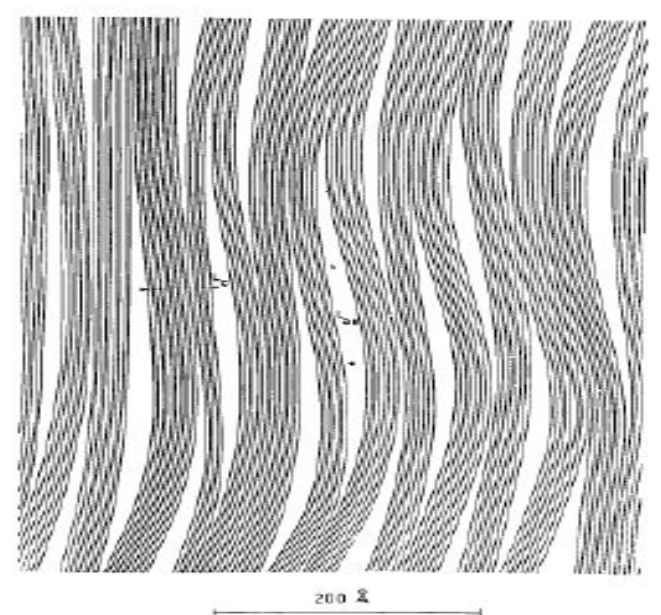

Figure 3: PAN Carbon Fiber Microstructure [10]

\section{Mesophase Pitch (MP) Carbon Fiber}

Mesospheres pitch constructs carbon fibre show high malleable properties due to its high organized nuclear structure and high crystalline of graphite. They can be set up at a low-fetched state, because of their materials and high carbon yield. Around $90 \%$ of the carbon strands conveyed are created utilizing polyacrylonitrile (PAN). The staying $10 \%$ CF is delivered utilizing rayon or oil pitch. These materials are normal polymers, portrayed by long arrangement of particles bonded with each other through carbon particles.

Edie et. Al. [11] stated that the surface of primarily commercial Mesophase Pitch (MP) carbon fibres was flat or radial as given in below diagram. In Axial direction, the molecular orientation can be produced by shear, if liquid state precursor moves in capillary tubes.

Gauguin and Oberlin [12] worked on the phase of high modulus PAN carbon fibre are same as MP carbon fibres, and these have 3 structures along with graphite, a micro porous turbostratic phase and a stage like great modulus PAN car- 
bon strands. These phases were divided anyway.

Diefendorf and Tokarsky [13] stated that circular dimensioning is preferred on the surface of MP carbon-fibre and the skin of this surface seems like an onion. Fig.1.4 shows the Microstructure of MP carbon-fibres.

Microstructure influences the properties of carbon-fiber, which is quite outstanding. Due to the presence of high substance, which is delocalized ( $\pi$ electrons) and parallel arrangement of layers of graphene along with carbon-fiber pivot, filaments of carbon demonstrated great warm and electrical conductivities in the fiber course, which were 21-125 W/MK respectively, which was just near of that metals [15]. On account of highly modulus carbon filaments of MP, the warm conductivity at room temperature could be more than $500 \mathrm{~W} / \mathrm{MK}$. The graphitized carbon's electrical conductivity is additionally near of those metals [15]. The high modulus (MP carbon filaments) with a highly precious stone introduction for the most part demonstrated a higher electrical conductivity than that of PAN carbon strands.

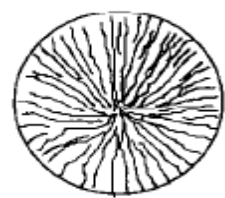

Radial

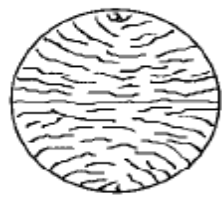

Flat-layer

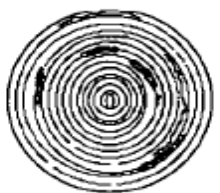

Onion-skin

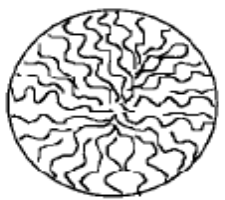

Radial-folded

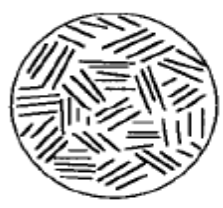

Random

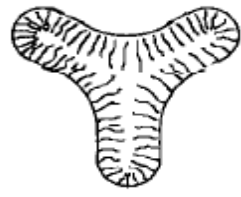

Line-origin

Figure 4: MP Carbon Fibers Microstructure [14]

\section{Pitch Carbon Fibers}

The ways of manufacturing of Natural and artificial pitch are different. Natural Pitch is made by damaging reefing of oil and coal, and other side artificial pitches are made with pyrolysis soft manufactured polymers. Eighty percent carbon can be contained by pitch and its arrangement with the source tar and preparing environment. The petroleum pitch has a less sweet smell than coal pitch. These pitch arrangements fluctuate with tar and manufacturing conditions.

Smith et al. [16] announced if coal tar pitch mixed at 2/3 has a sweet smelling, the rest all were heterocyclic. Sometime, coal pitch filament break due to more carbon contents involvement in expulsion and heat treatment. So, petroleum pitch was quite suitable for the production of carbon-fiber. In business area, petroleum pitch includes sweet-smelling mixes through sub-atomic load in scope of 400 to 600 [17]. Here, consumption of engineered pitch have pulled in supplementary happiness as of late, ever since it contains good quality and the adjustment can happen in the given rate of higher temperature.

Otani [18] detailed the creation of carbon filaments with polyvinyl-chloride (PVC) and contributed in 1965. The petroleum pitch was created by pyrolyzing polyvinyl-chloride (PVC) at temperature of around $400^{\circ} \mathrm{C}$ into nitrogen. Liquefied spinned filaments were oxidized with ozone, below the temperature of $70^{\circ} \mathrm{C}$ and into air, beneath temperature of $260^{\circ} \mathrm{C}$. Afterward, it carbonized at temperatures up to $500-1,350^{\circ} \mathrm{C}$ into nitrogen. Because of absence of the crystallite in- 
troduction, the Young's modulus of carbon-fibre of was around 49GPa and elastic worry was around 1.8GPa.hh

\section{Cellulosic Carbon Fibers}

The cellulosic carbon strands used in flax, cotton, sisal, and material, and recovered constant filaments as CF forerunners have been contemplated. Though rayon CF has been utilized economically and explored in general broadly, the manufacturing of Rayon is costly.

Despite the fact that rayon textures are yet to be utilized to change over into the CF material, the generation of carbon strands, since rayon has constrained because of its high preparing expense, low carbon yield which is $20 \%-30 \%$ and restricted mechanical assets [19]. The inspection for the most part has been cantered on changing the degradation component to expand the carbon yield.

\section{Other Precursors Used to Make Carbon-Fibers}

Scientists keep on looking for CF precursors with minimal effort, high carbon substance and bio renewability. The cost of carbon filaments increased due to precursors and capital hardware for changing the precursor. Bio renewable lignin is examined as major precursor element for carbon-fiber, because it was mainly with numerous phenolic mixtures. These days, crushing compound pulping processes are known as Kraft procedure.

Otani et. al. [20] certified the procedure for making of carbon filaments by lignin in the starting of 1969. Likewise, Sudo et al. [21-22] made CF by lignin that has genuinely great mechanical properties.

\section{Materials Used for Other Precursor}

Numerous different polymers have additionally been researched for their probable as CF forerunners. Although cellulosic strands talked about before, the other common filament has been explored together with silk [23]; Chitosan [24] and eucalyptus tar pitch [25]. These materials have the capability of bringing down creation price. Notwithstanding, a large portion of them are utilized as broadly useful carbon filaments, which don't give high mechanical properties. Engineered polymers have likewise been assessed as option for $\mathrm{CF}$ antecedents. Commonly, Electric protected a persistent procedure to change over polyacetylene strands to CF filaments [26].

\section{PRECURSOR MANUFACTURING METHODS}

In the manufacturing of $\mathrm{CF}$, pitch typically has a molecular weight of $200-300 \mathrm{~g} / \mathrm{mol}$ [27], while molecular weights of up to $1000 \mathrm{~g} / \mathrm{mol}$ [28] may be extracted, and is comprised of various complex, aromatic hydrocarbons. Petroleum and coal tar pitch is isotropic in nature, which can be used to manufacture the general purpose grade pitch based carbon fiber. In order to produce higher performance pitch based carbon fibers, the isotropic pitch must undergo thorough treatment in order to convert to a Mesophase pitch, which contains an anisotropic phase and graphitic structure.

\section{Stabilization, Carbonization, and Graphitization}

MP based precursor fibers are offset into the wind (or other oxygenating environments) at temperatures between the temperature of $250{ }^{\circ} \mathrm{C}$ and $350{ }^{\circ} \mathrm{C}$. Immediately following stabilization, the fibres are carbonized. As the temperature increases, the final carbon fibre tensile strength [29] and tensile modulus [30], which can be seen in the graphic form with tensile strength once again, as a defect limited property. Goma and Oberlin [31] investigated the microstructure of a graphitizing alkali halide crystal film prepared by condensation with increasing molecular order and at same raised heat treat- 
ment temperature. At carbonization temperatures between $800{ }^{\circ} \mathrm{C}$ and $1500{ }^{\circ} \mathrm{C}$, the microstructure comprised of distorted isolated columnar structures. As the carbonization temperature was increased to temperatures between $1500{ }^{\circ} \mathrm{C}$ and $1700{ }^{\circ} \mathrm{C}$, the observed microstructure was described as wavy ribbons. Finally, stiff straight carbon layers were observed at graphitization temperatures above $1900{ }^{\circ} \mathrm{C}$ [32]. As a result of these observations, it can be seen that the structure development during pitch heat treatment is a series of complex events.

Conversion of the PAN fibre into a carbonized structure requires two heat treatment processes, namely stabilization and carbonization. Traditional stabilization processes utilize the heat treatment of the fibre in an oxidative environment at temp 200 to $300{ }^{\circ} \mathrm{C}$, while these filaments are subjected to an applied tension. The fibres are subsequently subjected to the carbonization process, where the temperatures range from $\sim 1000{ }^{\circ} \mathrm{C}$ to greater than $3000{ }^{\circ} \mathrm{C}$. Studies focused on optimizing the carbonization temperature have shown that the tensile modulus continues to increase with the temperature of carbonization increases, while the tensile strength reaches a maximum at $\sim 1500{ }^{\circ} \mathrm{C}$. [33]

During stabilization in the oxidative environment at temperatures from $200{ }^{\circ} \mathrm{C}$ to $300{ }^{\circ} \mathrm{C}$, the polyacrylonitrile macromolecules undergo a transformation from a linear polymer to a rigid, thermally stable ladder structure [34]. Formation of the stabilized and carbonized PAN structure given in Figure 3, was proposed based upon NMR and XPS data [3536], although there are numerous studies focused on the stabilization reaction of both PAN homo polymers and copolymers [37].

\section{FABRICATION TECHNIQUES FOR CARBON FIBER}

Here, different types of techniques for assembling of composite parts are given. A couple of strategies have been getting on (implantation molding, for example), yet many were made to obtain a specific arrangement or amassing challenges. Assurance of a system for a particular part, thus, will depend on upon the materials:-

\section{Open Molding}

Open contact forming in uneven molds is an easy, regular procedure for making of CFC equipments. Normally, these are used in ship's infrastructure, RV segments, truck and taxis and car bumpers, bathroom things. Generally, substantial easy figures of open mold contain whichever hand lay-up, or a semi-mechanized option, spray up.

Hand lay-up and shower up methodologies are much of the time used as a piece to match for the reduction of labour work. For example, texture may first be placed in a locale exhibited to high extend; then, a sprinkle weapon might be used to apply to the severed glass and gum to build up, whatever is left of the cover. Balsa or foam focuses may be settled between the cover movies in either handle. Typical Carbon fiber size is $15 \%$ with shower up and $25 \%$ with hand lay-up [38].

\section{Resin Infusion Process}

Whenever the demand of faster production increased in the industry, it pushed the hand lay-up method at corner, and we think about the alternative process for faster and better production.

A typical option is Resin infusion process, here and there, it is known to as fluid trim. RIF is a genuinely straightforward procedure: It starts with a two-section, coordinated, close mold that is prepared by metal or compound material. Dry support (ordinarily perform) is put into molds and the mold is shut. Resin and catalyst are metered and blended in administering hardware, then driven into the mold under the short to direct weight through injection ports, completing pre- 
designed ways they perform [38]. To a great degree, low-thickness pitch is utilized as a part of RTM claims for dense parts to saturate, performs rapidly and equitably over cure. Both mold and resin can be warmed, as fundamental, for specific applications. RTM produces portions without an autoclave. Even so, when treated and remoulded, a section bound for a high-temperature application more often than not experiences post cure. Most RTM applications of two-section epoxy plan utilize.

A run of the mill case is Resin implantations prepare, all over it is referred to as liquid trim. RIF is a truly clear system: It begins with a two-segment, composed, close form that is set up of metal or compound material. Dry support (usually perform) is put into form and shape is closed. Gum and impetus are metered and mixed in controlling equipment, then crashed into the form under the shortest of direct weight through infusion ports, finishing predesigned ways they perform. To an extraordinary degree low-thickness, pitch is used as a piece of RTM cases for thick parts to immerse performs quickly and fairly in advance of cure. Both shape and pitch can be warmed, as central, for particular applications. RTM produces divide without an autoclave. All things considered, when treated and remoulded, an area destined for a hightemperature application, as a rule encounters post cure. Most RTM utilizations of two-segment epoxy arranges use [39-40]

\section{Resin Infusion Process}

It relates to many fast growing fabrication procedures that speak to the quickest developing new embellishment innovation. The notable comparison between VARTM and RTM is that, resin is drawn into perform from side to side utilization of a vacuum, just instead of pumped in underweight. VARTM does not need high heat or weight. Hence, VARTM works with ease tooling, making it feasible to economically deliver extensive and complex parts in one shot [38-41].

It is identified with many quickly developing creation techniques that address the speediest growing new adornment advancement. The outstanding analyse amongst VARTM and RTM is that, tar is drawn into perform from side to side use of a vacuum only, rather than directed in underweight. VARTM does not require high warmth or weight. Consequently, VARTM works as effortless tooling, making it possible to financially convey broad, complex parts in one shot [42].

\section{Resin Film Infusion (RFI)}

It is a procedure, where a dry perform with various layers of material with high thickness of resin (gum). After that heat, weight and vacuum, melted pitch is poured into the mold, which results resin distribution in a uniform manner, yet with high thickness, moreover reinforced tear maintain due to the best manner of resin flow [38-39].

\section{Pultrusion}

This method is used for carbon fiber and glass fiber for the last many decades, but from the last ten years, it has found various applications, especially in advance composite applications [38]. This method is relatively simple, cheaper cost and continuous process. In this, the composite fiber usually pulled from a heated resin tub after that, formed into particular design and shapes. Now, composite material has passed through a heated die, where it cures and takes its net shapes. After that, it should leave for cooling [43-44-45].

\section{Injection Molding}

It is a quick, high-volume, low weight, shut procedure utilizing and the most regularly filled thermoplastics, for example, nylon with slashed glass fiber. In the past 20 years, in any case, robotized infusion trim of BMC has assumed 
control over a few markets before, hand held by thermoplastic and metal throwing producers [38].

In the BMC infusion shaping procedure, a screw-sort plunger constrains a meteor shot of material with a warmed barrel and infuses it (at 5,000 to 12,000 psi), obsessed by a shut warmed mold. In that mould, the melted BMC streams effectively move along runner channels and into the shut mold. After cure, parts require just negligible wrapping up. Infusion velocities are ordinarily 1 to 5 seconds, and upwards of 2,000 little portions can be delivered every hour in specific numerous pit molds [46].

\section{APPLICATION OF CARBON FIBER}

\section{Application in the Sports}

There are various fields in sports, where CF is utilized like in Frames of bicycle, helmets, In ice stick hockey game, in motor racing vehicles, golf sticks, tennis rackets moreover in gliders, on surf boards, softball bat and fishing $\operatorname{rod}[1-47-48]$.

\section{Application in the Automotive Industry}

Carbon fiber comes in the advance composites materials. Due to its excellent mechanical properties, this is widely used in automotive industry. This is utilized in racing cars chassis, Outer surface of Car, mufflers, in steering wheels, into the roof of car, many interior parts of car, hoods, the bumpers of the cars, in seat cover of cars, in propeller shaft, compressed tank and many other parts of automotive industry [1-2-49-50].

\section{Application in the Aircraft}

This is well justified that carbon fiber has excellent mechanical properties. The main thing which makes it more popular is its light weight, high strength, good corrosion resistance, excellent design flexibility and excellent thermal insulation property. Because of it this, it is more favourable in Aerospace or Aircraft field [51]. Today, this is widely used in satellite, rockets, into the main wings of Aircraft, fuse legs, Rudders, Flore panel, Beams, In airplane Seats, Elevators, Lavatory units and on the front Nose of Airplane[52].

\section{Applications in the Medical Field}

Moreover, due to these upper outstanding properties discussed, Carbon fiber is also very useful in medical areas e.g. Cradles, couches, pallet, radiographic imaging, table tops, surgical table parts, positioning items etc. This is also used in knee for ligament treatment and in front broken bone treatment of leg [53-54].

\section{Some other Applications in Industry}

Hence, Carbon fiber is used in many other components like in body for high-speed train, for the Bridge pier reinforcement, in X-ray top panel, in PC housing and in the Robotic hand for liquid crystal panel [38-47-53].

\section{LITERATURE SURVEY}

The entire document should be in Times New Roman. The font sizes to be used are specified in Johnson and Thorne [55], who have taken a stab at utilizing oxidation to expel surface blemishes for enhanced fiber quality. Subsequent to treat the $\mathrm{CF}$ in the wind for around ten minutes, they watched a 75\% expansion. Thorne [56] enhanced fiber elasticity by around $68 \%$ by warmth treatment of carbon strands with a mixture of carbon-dioxide $(\mathrm{CO} 2)$ and acetylene at temperature around $700^{\circ} \mathrm{C}$. This statement on carbon $(\mathrm{C})$, regarding fiber face mended blemishes, adding two enhanced properties. In- 
dia [57] find that high rigidity in MP Carbon strands that may demonstrate the turbo-stratic formation. The collapsed turbostratic structures have additional tortuosities that ruine break spread.

DB, et al. [58] explored the compressive disappointment of carbon strands by analysing the SEM pictures after the backlash trial. They watched PAN carbons which were in high modulus filaments clasped when in pressure. The disappointment started from one side with strain, though the opposite side on pressure shaped wrinkle groups. For the high modulus Mesophase pitch (MP) carbon filaments, because of the better introduction of carbon sheets, the compressive disappointments were during a shear system, which resulted in a wrinkle tilted at $45^{\circ}$ angle too inclined with fiber pivot.

Hahn et. al. [59] arranged uni-directional composites utilizing T-700 PAN and T-300 PAN Carbon strands by Toray and (P-75) Mesophase pitch CF by Amoco. These two inferred that the PAN strands flopped, because of micro buckling although MP carbon fiber framed a band, which was in shear. The Fiber torsional practices are additionally identified with microstructure. Contrasted and PAN carbon strands, MP carbon filaments indicates bringing down of torsional modulus on the grounds that, their outspread structure encourages shear among the layers. The exceptionally irregular conveyance of the plane layers in a cross-segment fiber added to the greater modulus of torsional of (PAN) carbon strands.

C. Elanchezhian et.al [60] experimentally investigated the mechanical properties of carbon and glass fiber reinforced composites (GFRCs) at various temperatures and strain values. They used the hand lay-up procedure to fabricate both the test pieces. They worked on the impact, tensile and flexural properties of both materials. They observed that carbon fiber reinforced polymer (CFRP) composite has better properties than Glass fiber reinforcement polymer (GFRP) composites in both flexural and tensile properties. The scanning electron microscope (SEM) technique is used for the observation of the internal micro structure of composite materials in this work. In comparison of both materials, CFRP composite have $36.262 \mathrm{KN}$ more value of tensile test than GFRP composite. Like tensile properties, the flexural strength of the CFRP composite is comparatively more than GFRP composite, which is $1.785 \mathrm{KN}$, as the CFRP composite have high impact strength than GFRP composite. Its value is 5-6 J.

Amos Gilat et. Al [61] conducted an experimental analysis to study the effect of strain rate on a carbon / epoxy composite. In this study, they tested various resins and laminate configurations at various strain values. Using hydraulic machine, the tensile test was conducted. They found that when the strain rate increases, the stiffness value also increases.

Fitz et.al. [62] Gave suggestions that exclusive 2 spaces of a micro porous and thick structure stage existed. These micro domains were shaped amid turning, and the association happened inside areas amid the resulting heat treatment. Some carbon filaments additionally display a sheath-centre structure. Strips in the fiber canter had favoured outspread appropriation, and the layers between the surfaces had a tendency of a round shape framing, which had skin like onion.

Huang et. al.[63] affirmed that the presence of sheath-centre formation in (PAN) carbon filaments utilizing spectroscopy of Raman. Two districts in antecedent strands were in charge of arrangement of sheath-centre formation in resulting CF (carbon filaments).

Mrinal C. Saha and Junfeng Laing [64] experimentally investigated the effect of the carbon nano fibers on thermal conductivity of carbon fiber reinforced composites. They conclude that, when we do arbitrary orientation of the CNFs on the fiber surface, which results progress in the in-plane direction. Moreover, CNFs growth finds $33 \%$ enhancement when they added it into CRFCs.

Lin-Zhi Wu et. Al [65], experimentally investigates the thermal and mechanical behaviour of carbon fibre poly- 
mer matrix composite. They manufactured the z-filter laminated composites by periodically filling copper sphere and coating aluminium's foils. Their results depict that the thermal conductivity is increased by z-filler compositions, and when we increase the z-filler volume fraction, then results show, interfacial thermal resistance decreases.

Maozhong Yi, Shaw Wu et.al [66] studied on the tensile strength of carbon fiber composite. They were using the pyro carbon for interface formations. They observed that using pyro carbon composition voids, defect increases on the surface of carbon fiber and results decrease the tensile strength and mechanical strength.

Julia Brunbauer, Hannes et.al [67] investigated on fatigue strength and microstructure of carbon fiber laminate composite. They were using the epoxy resin and scanning electronic microscope (SEM) for the microstructure. The outcome was that, fatigue depended upon load of fiber content. The low fiber content decreases the fatigue strength, and load higher fiber content decrease fatigue strength.

H. Kin et.at [68] studied about work on processing - microstructure - property relationship for carbon fiber composites reinforced with carbon nanotubes and Nano fibers. Today, Carbon nanotube is very popular and very effective in carbon fiber reinforcement. But, this is an expensive technique to include carbon nanotubes into Carbon fiber composites. So, he suggested about more effective and economical working method that should be invented in the future.

\section{CONCLUSIONS AND FUTURE PROSPECTS}

MP and PAN are the two most predominant precursors used in the production of carbon fiber. The thing, which comes out is that major work regarding carbon fiber structure's impact on its properties and to reduce the production cost or to improve the fiber properties have been done. However, the challenges of cost reduction, improvements in tensile strength and compressive strength remain still. Researchers need to focus on cost reduction and quality improvement. On another hand, the substitute precursor's improvement also remains still. Through decreasing the flow sensitivity and by improving the microstructure of fiber, we can improve the strength of carbon fiber. The structure of CF is directly related to precursor morphology and working circumstances. Studies in these two fields will help in improving carbon fiber for better results. For the improvement of carbon fiber efficiency, the size of crystallite, shape, size and circulation by shifting preparing parameter and their impact on their properties should be investigated. Important things which influence structure are that, the $\mathrm{CF}$ microstructure relies upon the precursor and preparing conditions. There are some polymers like P.E and Lenin, such as less expensive carbon fiber precursor's materials. These materials reveal new ways for low cost carbon fiber. However, insufficient work has been done on the procedure improvement. The stabilization time shortening should be done by different methodologies. Sometimes, the mechanical properties of the resultant carbon filaments are affected through heat stretching that should be investigated. Overall, more studies need to be done in optimizing the structure, precursors, mechanical properties and working conditions to improve the material properties.

\section{REFERENCES}

1. Roberts, T. The Carbon Fiber Industry: Global Strategic Market Evaluation 2006-2010; Materials Technology Publications: Watford, UK, 2006; pp. 10, 93-177, 237.

2. Fitzer, E.; Edie, D.D.; Johnson, D.J. Carbon fibers-present state and future expectation; Pitch and mesophase fibers; Structure and properties of carbon fibers. In Carbon Fibers Filaments and Composites, 1st ed.; Figueiredo, J.L., Bernardo, C.A., Baker, R.T.K., Huttinger, K.J., Eds.; Springer: New York, NY, USA, 1989; pp. 3-41, 43-72, 119-146.

3. Committee on High Performance Synthetic Fibers for Composites, Commission on Engineering and Technical Systems, Na- 
tional Research Council. High-Performance Synthetic Fibers for Composites; National Academy Press: Washington, DC, USA, 1992; pp. 23, 56-64, 86.

4. Moeiyuki Onishi, Torey's business Strategy for Carbon fiber Composites material, Torey Ind. Inc. Sep. 2012.

5. Chung, D.L. Carbon Fiber Composites; Butterworth-Heinemann: Boston, MA, USA, 1994; pp. 3-65.

6. Donnet, J.B.; Bansal, R.C. Carbon Fibers, 2nd ed.; Marcel Dekker: New York, NY, USA, 1990; pp. 1-145.

7. Morley, J.G. High-Performance Fiber Composites; Academic Press: Orlando, FL, USA, 1987; pp. 46-78.

8. Xiaosong Hunay, Review Fabrication and Properties of Carbon fiber Materials, 2009,2, 2369-2403 (structure)

9. Johnson, W.; Watt, W. Structure of high modulus carbon fibres. Nature 1967, 215, 384-386.

10. Perret, R.; Ruland, W. The microstructure of PAN-base carbon fibers. J. Appl. Crystallogr. 1970,3, 525-532.

11. Edie, D.D, The effect of processing on the structure and properties of carbon fibers. Carbon 1998, 36, 345-362.

12. Guigon, M, Oberlin. A, Preliminary studies of mesophase-pitch-based carbon fibers: Structure and microtexture. Compos. Sci. Technol. 1986, 25, 231-241.

13. Diefendorf. R.J, Tokarsky. E, High-performance carbon fibers. Polym. Eng. Sci. 1975, 15, 150-159.

14. Edie, D.D. The effect of processing on the structure and properties of carbon fibers. Carbon 1998, 36, 345-362.

15. Konkin, A.A.; Watt, W. Properties of carbon fibers and fields of their application. Production of cellulose based carbon fibrous materials. Chemistry and physics of the conversion of polyacrylonitrile fibers into high modulus carbon fibers. In Strong Fibers; Watt, W., Perov, B.V., Eds.; Elsevier Science Publishers: Amsterdam, The Netherlands, 1985; pp. 241-273, 275-325, 327-387.

16. Smith, F.A.; Eckle, T.F.; Osterholm, R.J.; Stichel, R.M. Manufacture of coal tar and pitches. In Bituminous Materials; Hoiberg, A.J., Ed.; InterScience Publishers: New York, NY, USA, 1966; Vol. 3, p. 57.

17. Barr, J.B.; Chwastiak, S.; Didchenko, R.; Lewis, I.C.; Lewis, R.T.; Singer, L.S. High modulus carbon fibers from pitch precursors. Appl. Polym. Symp. 1976, 29, 161-173.

18. Otani, S. On the carbon fiber from the molten pyrolysis products. Carbon 1965, 3, 31-38.

19. Peebles, L.H. Carbon Fibers: Formation, Structure, and Properties, 1st ed.; CRS Press: Boca Raton, FL, USA, 1994; p. 3.

20. Otani, S.; Fukuoka, Y.; Igarashi, B.; Sasaki, K. Method for producing carbonized lignin fiber. US Pat. 3461082, 1969.

21. Sudo, K.; Shimizu, K. A new carbon-fiber from lignin. J. Appl. Polym. Sci. 1992, 44, 127-134.

22. Sudo, K.; Shimizu, K.; Nakashima, N.; Yokoyama, A. A new modification method of exploded lignin for the preparation of a carbon fiber precursor. J. Appl. Polym. Sci. 1993, 48, 1485-1491.

23. Majibur, M.; Khan, R.; Gotoh, Y.; Morikawa, H.; Miura, M.; Fujimori, Y.; Nagura, M. Carbon fiber from natural biopolymer: Bombyxmori silk fibroin with iodine treatment. Carbon 2007, 45, 1035-1042.

24. Bengisu, M.; Yilmaz, E. Oxidation and pyrolysis of chitosan as a route for carbon fiber derivation. Carbohydr. Polym. 2002, $50,165-175$.

25. Prauchner, M.J.; Pasa, V.M.D.; Otani, S.; Otani, C. Biopitch-based general purpose carbon fibers: Processing and properties. Carbon 2005, 43, 591-597.

26. Sliva, D.E.; Selley, W. Continuous method for making spinnable polyacetylene solutions Convertible to high strength carbon 
fiber. US Pat. 3928516, 1975.

27. Bright AA, Singer LS. The electronic and structural characteristics of carbon fibers from mesophase pitch. Carbon 1979;17:59-69.doi:http://dx.doi.org/10.1016/0008-6223(79)90071-X.

28. Barr JB, Chwastiak S, Dudchenko R, Lewis IC, Singer LS. High modulus carbon fibers from pitch precursor. Applied Polymer Symposium 1976;29:161.

29. Morgan, P. “CARBON FIBERS and their Composites” 2005: CRC Press.

30. Suang V. Hoa, "Principles of manufacturing of composite Materials" Destech Publications, Inc. 2005.

31. Goma J, Oberlin M. "Graphitization of thin carbon films Thin Solid Films" 1980;65:221,32. doi:http://dx.doi.org/10.1016/0040-6090(80)90256-4.

32. Chen, Y. and D. Chung, In situ Al-TiB composite obtained by stir casting. Journal of materials science, 1996. 31(2): p. 311315.

33. Matsumoto T. Mesophase pitch and its carbon fibers. Pure and Applied Chemistry 1985;57:1553-62.

34. Gupta AK, Paliwal DK, Bajaj P. Acrylic Precursors for Carbon Fibers. Journal of Macromolecular Science, Part C 1991;31:1-89. doi:10.1080/15321799108021557.

35. Morita K, Murata Y, Ishitani A, Murayama K, Ono T, Nakajima A. Characterization of Commercially available PAN-based carbon fibers. Pure and Applied Chemistry 1986;58:455-68.

36. Takahagi T, Shimada I, Fukuhara M, Morita K, Ishitani A. XPS studies on the chemical structure of the stabilized polyacrylonitrile fiber in the carbon fiber production process. Journal of Polymer Science Part A: Polymer Chemistry 1986;24:31013107. doi:10.1002/pola.1986.080241134.

37. Bashir Z. A critical review of the stabilization of polyacrylonitrile. Carbon 991;29:1081-90. doi:10.1016/00086223(91)90024-D.

38. Jeff Sloan, "Fabrication methods" Composites World, Gardner business Media Inc, 2016

39. F. Sancheza, Domenecha V. Garcla "Fast and reliable gate arrangement pre-design of Resin Infusion Processes" Elsevier Ltd. 285-292, 77, October 2015

40. Leslie E. Letterman, Seattle Wash the Boeing Company, Seattle Wash 679,427, Nov 111986

41. Xiaolan Sung “Desecration submitted to the faculty of the Virgima Polytechnic institute and state university” April 142013

42. Nasim Uddin, Uday K. Vaidya, Muhammad shohel “Vacuum-Assited Resin Transfer Molding” Concrete International, 28, 5356, 11 Jan 2006

43. Raymond W. Meyer "Handbook of Pultrusion Technology" Chapman and Hall, New York, London 1985

44. Trevor F Starr "Pultrusion for Engineers" Boca Raton, FL : CRC Press ; Cambridge : Woodhead Publishing, 2000. $1855734257: 0849308437$ (CRC)

45. Edby Bikale P "Moulding of Plastic” 12-13, Wiley Interscience, New York 1971

46. David C King, Rupert M. Lillis, George White "Process for the Injection "Moulding of Multi-layered articles" US5188787 A, US 07/913,961 Du Pont Canada Inc. 23 Feb. 1993

47. Chris Red, Jeff Sloan "Market outlook carbon fiber in sporting goods" Composites World1 Jan 2008, Gardner business Media Inc, 2017 
48. Dodd H. Grande, Steve Criest, Tyler Jessie, Jason Denial “Composites in Sports Application” References module in Material science and Material engineering” Elesvier Ltd. 2017

49. Daniel Gay "Composite materials Design and applications" CRC Press, Taylor and Francis Corp. 13:978-1-4665-8487-7, 2015

50. James Holbery and Dan Housten "Natural-Fiber-Reinforcement-Polymer composites in Automotive Applications" JOM, Nov. 2006

51. Nikhil V Nayak, "Composite Materials in Aerospace Applications" International journal of science and research, ISSN 22503153, Sep 2016.

52. Takayuki Koyama "Development of CFRP (Carbon fiber reinforced Plastic) Monolithic Sandwich Construction" Mitsubishi Heavy Industries Technical Review, Dec 2014.

53. S. Ramakrishna, J. Mayer, E. Wintermantal, Kam W. Leong “Composite Science and Technology” Biomedical Applications of Polymer Composites Material A Review, July 2001,1189-1224

54. Erich Fitzer "Review Article, The future of Carbon Fiber Composites" Pergamon Journals Ltd. 1987, 163-190,0008-6223/87

55. Johnson. J.W, Thorne. D.J, Effect of internal polymer flaws on strength of carbon fibers prepared from an acrylic precursor. Carbon 1969, 7, 659-660.

56. Thorne. D.J, Coating of carbon fiber with carbon,1972. DE 2128526,

57. Endo. M, Structure of Mesophase pitch-based carbon fibers. J. Mater. Sci. 1988, 23, 598-605.

58. Dobb, M.G, Johnson, D.J.; Park, C.R, Compressional behavior of carbon-fibbers. J. Mater. Sci. 1990, 25, 829-834.

59. Hahn. H.T, Sohi. M.M, buckling of a fiber bundle embedded in epoxy. Composite Science Technology, 1986, 27, 25-41.

60. Elanchezhian. C, R.B. Vijaya, Hemalatha.J, J.Hemalatha "Mechanical behavior of glass and carbon fibre reinforced composites at varying strain rates and temperatures" Procedia Materials Science 6( 2014 ) 1405 - 1418

61. G. Amos, K. Goldberg, Experimental study of strain-rate-dependent behavior of carbon-epoxy composite, Composites science and technology 62 (2002) 1469-1476.

62. Fitz Gerald. J.D, Pennock. G.M, Taylor. G.H, Domain structure in MP (Mesophase pitch)-based fibres. Carbon 1991, 29, $139-164$.

63. Huang. Y, Young. R. J, Effect of fiber microstructure upon the modulus of PAN-and pitch-based carbon fibers. Carbon 1995, $33,97-107$.

64. S. Mrinal D. L, Junfeng. A. M, Cengiz, Effect of carbon nanofibers on thermal conductivity of carbon fiber reinforced composites, Procedia Engineering 56 (2013) 814-820.

65. Wu Lin-Zhi, Y. Guo-Cai, F. Li-Jia, Thermal and mechanical properties of carbon fiber polymer-matrix composites with a 3D thermal conductive pathway, composite Structures 149 (2016) 213-219.

66. Yi Maozhong, Wu Shuai, surface structure of PAN-based fibres and their influences on the interface formation and mechanical properties of carbon-carbon composites, Part-A 90 (2016) 480-488.

67. Braunbauer julia, Stadler hannes, Pinter Gerald. Mechanical properties, fatigue damage and microstructure of carbon/epoxy laminates depending on fiber volume content, international journal of fatigue 70(2015) 85-92.

68. Kim. H, Hahn H. T, Bekyarova "Carbon fibre composites reinforced with carbon Nano materials" 18th international confe- 
rence on composite materials, August, 2011, in JeJu Island, Korea. Korea Institute of Science and Technology1 Jeonbuk, Korea, Mechanical and Aerospace Engineering Department, UCLA, Los Angeles, USA2 3 Carbon Solutions, Inc., Riverside, USA3, Dept. of Chemical Engineeringartment, POSTECH, Pohang, Korea4. 